\title{
Estilos y lógicas de acción territorial. La experiencia reciente de los municipios del Paraguay
}

\section{Marcelo Sili 12}

${ }^{1}$ Consejo Nacional de Investigaciones Científicas y Técnicas (CONICET), Buenos Aires - Argentina

2 Universidad Nacional del Sur / Departamento de Geografía y Turismo, Centro ADETER, Bahía Blanca - Argentina

La acción territorial es un complejo proceso de construcción del desarrollo en el cual intervienen la acción pública, la privada y la colectiva. Como lo demuestra la experiencia latinoamericana, los municipios son actores de creciente importancia en la dinámica de construcción del desarrollo local. Sin embargo las formas de actuación de los municipios no son iguales. Al contrario, este trabajo muestra profundas diferencias de estilos y formas de intervención entre todos ellos. Pudimos identificar cuatro tipos o estilos de acción que sintetizan dos grandes elementos. En primer lugar, las formas de organización para la obtención de recursos y, en segundo, los tipos de acciones priorizadas para construir procesos de desarrollo y para reducir problemas de pobreza estructural.

Palabras clave: acción territorial; municipios; desarrollo territorial; Paraguay.

\section{Estilos e lógicas de ação territorial. A experiência recente dos municípios do Paraguai}

A ação territorial é um processo complexo de construção de desenvolvimento em que intervêm a ação pública, a ação privada e a ação coletiva. Como mostra a experiência latino-americana, os municípios são atores de crescente importância na dinâmica de construção do desenvolvimento local. No entanto, as formas de ação dos municípios não são as mesmas. Pelo contrário, este trabalho mostra diferenças profundas em estilos e formas de intervenção entre todos eles. Fomos capazes de identificar quatro tipos ou estilos de ação, que sintetizam dois grandes elementos. Em primeiro lugar, as formas de organização para obter recursos e, segundo, os tipos de ações priorizadas para construir processos de desenvolvimento e reduzir os problemas de pobreza estrutural.

Palavras-chave: ação territorial; municípios; desenvolvimento territorial; Paraguai.

\section{Styles and logics of territorial action. The recent experience of the municipalities of Paraguay}

Territorial action is a complex process of development in which public, private, and collective actions intervene. As the Latin American experience shows, municipalities are increasingly important actors in building local development. They act in different ways, and this work highlights these differences in style and form of intervention. The study identifies four types or styles of action that synthesize two main elements. First, the forms of organization for obtaining resources. Second, the types of actions prioritized to build development processes and reduce problems of structural poverty.

Keywords: territorial action; municipalities; territorial development; Paraguay. 


\section{INTRODUCCIÓN: NUEVOS MUNICIPIOS, NUEVOS TERRITORIO}

El modelo territorial histórico del Paraguay estuvo estructurado en base a pocas ciudades de poca población, ligadas al sector público y al comercio, y que estaban rodeadas por áreas rurales donde predominaba una densa agricultura familiar y campesina, con cientos de pequeños poblados y asentamientos, históricamente complementarios a la estancia ganadera y a los obrajes. En las últimas décadas este modelo territorial fue cambiando, se hizo más complejo, caracterizándose por varios factores concomitantes. Entre ellos el creciente peso de ciudades de todos los tamaños, con incipientes industrias y con un firme proceso de descentralización de los servicios urbanos, en especial financieros y educativos, y el comercio mayorista (Vázquez, 2013). Paraguay vive así un proceso de transformación singular, de pasaje entre un modelo territorial caracterizado por una baja movilidad espacial, la presencia de una fuerte economía campesina, el aprovechamiento de pocos recursos y una mirada endógena, hacia un modelo más abierto, de fuerte movilidad espacial, descentralización y ligado a la exportación de energía y productos agropecuarios por parte de grandes propietarios de la tierra (Verdecchia, 2007).

Desde el punto de vista urbano, la Capital (Asunción) y las ciudades del "interior" habían tenido un funcionamiento jerárquico y centralizador, con sus centros históricos (plaza, iglesia, policía, comercio y gobierno) que presidían a barrios integrados. Este esquema está cambiando, hoy toda la región metropolitana de Asunción (y sus ciudades periféricas) crece notablemente, pero la capital Asunción se mantiene estable aunque mantenga su liderazgo. Otros ejes urbanos crecen notoriamente, dinamizados por el desarrollo de los agronegocios (principalmente producción de cereales y oleaginosas de gran escala) y el comercio (Concepción, Encarnación, Ciudad del Este, Pedro Juan Caballero, etc.) (Vázquez \& Goetz, 2013).

Las áreas rurales también se han vuelto más complejas. Persiste la agricultura familiar, pero con pautas familiares no tradicionales, modificada por la nueva tecnología de las comunicaciones y por el acceso al transporte personal barato (motos de bajo costo que aseguran la movilidad en las áreas rurales); en muchas zonas se está consolidando una economía de agricultura familiar campesina prospera, hortícola y frutícola que provee a las ciudades. Se conforma además una agricultura empresarial dinámica e internacionalizada, con fuerte posicionamiento internacional (desde el 2012 Paraguay es sexto productor y cuarto exportador mundial de soja y noveno exportador de carne bovina, constituyendo entre ambos el 65\% de sus exportaciones y el 25\% del PIB), posicionamiento liderado por un conjunto importante de empresas multinacionales como Cargill, ADM, Bungue Paraguay S.A., Monsanto, Agrotec S.A. y Luis Dreyfus Paraguay S. A. las cuales pasaron a ser actores de relevancia en el ámbito territorial local (Cámara Paraguaya de Exportadores y Comercializadores de Cereales y Oleaginosas [CAPECO], 2013; Guereña, 2011; Programa de las Naciones Unidas para el Desarrollo [PNUD], 2010; Riquelme \& Vera, 2013; Rojas, 2009; Ruiz, 2008).

Dentro de esta dinámica de transformación territorial, se evidencia una fuerte tensión entre los múltiples actores y sus proyectos de futuro. Por ejemplo, los sectores empresariales pugnan por controlar territorios, aumentar la competitividad y desarrollar economías de exportación: silos, industrias, puertos y barcazas para el transporte de granos. Los campesinos por otro lado pugnan por mantener sus territorios y colectividades, por no ser desplazados. Estas dinámicas de control 
territorial evidencian diferentes formas de entender e interpretar el territorio y el desarrollo, para algunos como sinónimo de espacio para la producción, el crecimiento y la acumulación, para otros como sinónimo de mejora de la calidad de vida y el arraigo. A esta última advocación se suman las colectividades originarias recientemente asimiladas al Estado Nación, que, aunque minoritarias tienen sus propios reclamos étnicos y territoriales.

Como resultado se observa en el país la emergencia de numerosas iniciativas tales como planes, programas y proyectos de desarrollo de todo tipo, los cuales evidencian y traducen múltiples objetivos, como los de superar los procesos de crisis de aquellos territorios que no se benefician de las dinámicas de crecimiento económico o no sortean la competencia; o, los de captar nuevas oportunidades económicas y productivas en los territorios más dinámicos, intentando así consolidar escenarios de mayor crecimiento, con una regulación estatal favorable, y la consolidación de la inserción de la agroindustria local en cadenas de valor internacionales. Esta multiplicidad de iniciativas es construida desde el Gobierno Central, desde las Gobernaciones y las municipalidades, y también desde el sector privado (empresas, productores, etc.) y las organizaciones sociales, las cuales cobran cada vez más importancia. Interesa observar que muchas veces estas iniciativas están signadas por la superposición, los conflictos y la competencia entre ellas, lo cual, en la mayor parte de las veces, lleva a la pérdida de la eficacia y del impacto de las mismas, o a juegos de sumas negativas, en donde nadie gana.

Dentro de este nuevo contexto de profundas transformaciones territoriales y de multiplicidad de iniciativas para el desarrollo, las Municipalidades tienen un rol cada vez más importante. En efecto, en Paraguay, como en la mayor parte de los países de América Latina las Municipalidades se han transformado en actores clave para el desarrollo de sus territorios (Aghón \& Cortés, 1998; Nickson, 2016; Victory, 1999). De ser Organismos preocupados por problemas de mantenimiento de la planta urbana, y el mantenimiento de las calles, recolección de basuras, etc., pasaron a ser organismos responsables de la promoción y el desarrollo del conjunto del territorio, lo que incluye las ciudades y las áreas rurales de población dispersa. Sin embargo, los municipios no actúan todos de la misma manera, al contrario, hay una gran diversidad de estilos que depende de la visión que se tiene del desarrollo, de las condiciones territoriales, de los modelos de gobernanza y articulación de actores, y de los recursos con los que cuentan, los cuales suelen ser limitados. La combinación de estos factores define diferentes estilos de gestión o acción territorial que finalmente terminan potenciando o inhibiendo dinámicas de desarrollo.

Desde el punto de vista analítico, y en vistas a potenciar los procesos de desarrollo territorial a escala municipal, el objetivo de este trabajo no es realizar un diagnóstico sobre el funcionamiento de los municipios de Paraguay sino describir y analizar los estilos de intervención de las Municipalidades en torno a los problemas de sus territorios y a la construcción de sus dinámicas de desarrollo. Una comprensión cabal de estos estilos permitiría definir mejores políticas de fortalecimiento institucional de nivel municipal, potenciando las oportunidades de desarrollo en el país.

Teniendo en cuenta este objetivo, la hipótesis que sustenta esta investigación es que existen en Paraguay municipios con estilos de acción territorial diversos y heterogéneos, que, además de dar cuenta de formas específicas de intervenir en la construcción del desarrollo y en la reducción de la pobreza, son reveladores de otros dos elementos claves. En primer lugar de las condiciones estructurales 
del territorio, es decir que cada tipo de estilo de acción territorial preanuncia un tipo de problemáticas de los territorios, de sus sistemas de producción y de sus realidades sociales. En segundo lugar, cada uno de estos estilos de acción territorial revela las representaciones que subyacen a la mentalidad de los intendentes y sus equipos de gobierno en torno al desarrollo de sus propios territorios, es decir que estos estilos de acción territorial son una manifestación de lo que estos actores creen que se debe y puede realizar en torno al desarrollo territorial.

\section{MARCO CONCEPTUAL DE REFERENCIA}

El análisis de los estilos de acción territorial de los municipios y la validación de esta hipótesis de trabajo se realiza utilizando como marco conceptual de referencia el concepto de "acción territorial", previamente desarrollado y discutido (Sili, 2018).

"Se entiende a la acción territorial como un proceso multiactoral de construcción y organización de territorios, pero cuyo devenir es incierto, pues depende de numerosas variables y condiciones $y$, sobre todo, del ideario de desarrollo y del poder que los propios actores involucrados posean y movilicen (Pouthier, 2013). Los resultados de la acción territorial pueden ser dispares, ya que no siempre son escenarios deseados de desarrollo. Al contrario, en muchas ocasiones la dinámica de la acción de los múltiples actores genera situaciones de mayor desequilibrio, deterioro o empobrecimiento de los territorios. En este sentido, la noción de acción territorial nos permite pensar el futuro de los territorios de una manera más descarnada y real, sin caer en la trampa del trayectorismo occidental (Appadurai, 2015) por la cual los territorios están sujetos y condicionados a seguir una línea de tiempo que inevitablemente nos conduce a escenarios de superación y progreso, y que siempre implicó que toda política e intervención en los territorios debe servir necesariamente para remover los obstáculos que frenan o impiden avanzar hacia ese escenario predestinado de progreso" (Sili, 2018, p. 12).

En otras palabras, la acción territorial es el proceso a partir de la cual una sociedad organizada a través de la acción pública, privada y colectiva, construye su proyecto territorial asociado a su propio ideario de desarrollo.

La acción territorial es necesariamente un proceso complejo, que integra el pasado, dada la memoria y las estructuras físicas heredadas, el presente por las condiciones de contexto actuales, y el futuro de acuerdo a las imágenes y representaciones que tenemos sobre las expectativas y emprendimientos deseados que determinan la intencionalidad en la toma de decisiones. Así, la acción territorial integra y coordina necesariamente múltiples y diversas iniciativas de actores con temporalidad y ritmos de vida muy diferentes, pues todos los actores y los grupos sociales involucrados no necesariamente siguen las mismas lógicas y las mismas rítmicas culturales, de allí que la acción territorial es también un claro generador de conflictos entre actores y grupos sociales, pues las acciones de unos chocan o limitan las acciones de otros actores. Las acciones territoriales no siempre son horizontales, ni benéficas para todos los actores o habitantes de un territorio, al contrario, pueden tratarse de acciones que contradicen las ideas y representaciones de desarrollo de otros actores.

Las estrategias para superar los conflictos que se generan a partir de la acción territorial de múltiples actores es una tarea sobre la cual no existen recetas claras, sino que constituye una tarea política y técnica de envergadura. Así, tal como lo plantea De Rubertis (2010): 
"Pertanto, è necessario individuare i meccanismi istituzionali che ogni comunità ha selezionato $e$ organizzato nel gestire i conflitti, al fine divalutare quanto i processi di pianificazione messi in atto si basino effettivamente su principi di democrazia partecipativa e quanto siano, invece, condizionati dai rapporti dif orza esistenti tra i soggetti e i gruppiche si confrontano"(De Rubertis, 2010, p. 10).

De esta manera, la acción territorial debe ser entendida desde una perspectiva de construcción y transformación de la sociedad y el territorio, como un ir haciendo en el territorio, contenidos por una estructura que condiciona (medio físico, condiciones político institucionales, etc.), pero también con un margen de maniobra y autonomía por parte de los sujetos, lo cual permite pensar y promover una visión optimista sobre las posibilidades de intervención y construcción de escenarios deseados (Lagarje, 2011). La acción territorial se sustenta claramente en el enfoque estratégico propuesto por la sociología de las organizaciones (Crozier \& Friedberg, 1977), pues son los juegos de los actores, a través de negociaciones sistemáticas, los que organizan el campo de acción o la arena de intervención del desarrollo. El actor de la acción territorial es según Crozier y Friedberg (1977) y más recientemente teorizado por Vanier (2015) un sujeto intencional, orientado hacia el futuro, un sujeto competente pues tiene capacidad para movilizar recursos, conocimientos e información sobre la realidad. Existe entonces implícitamente un reconocimiento de que "el actor no existe fuera de un sistema que define su libertad y la racionalidad que puede utilizar en sus acciones, pero también se reconoce que el (sistema) territorio no existe sin el actor que le da vida y puede transformarlo"(Crozier \& Friedberg, 1977, p. 11).

La adopción del enfoque estratégico propio de la sociología de las organizaciones se fundamenta claramente en la necesidad de entender la lógica y las formas de actuación de los múltiples actores involucrados en el territorio, lo cual incluye, tal como lo señalamos anteriormente, la cooperación y los conflictos como materia prima de los procesos de negociación. Así, tal como lo plantea Truda (2008):

"The Economic and social development always results a combination between different factors and actors. In a contest of territorial governance, originate the necessity of cooperation between the actors and the ability to adquire knowledges and competences. To know a territory require the collaboration of expert and actors and when the scientific aspect reconcile itself with the concrete aspect of the structure can act on a concrete problem of the territory" (Truda, 2008, p. 339).

Sobre la base de este reconocimiento del juego estratégico de los actores, pero con una mirada puesta en la construcción de territorios del futuro, Oosterbeek (2014) plantea la necesidad de construir una concepción más pragmática y constructiva para el desarrollo territorial, a través de lo que denomina la "Gestión integrada del territorio", por el cual la construcción de acciones para el desarrollo territorial:

"se apoiaram na compreensão de que conhecimento (do meio ambiente, da tecnologia e dos processos sociais) e logística são as bases de um processo que deve olhar o futuro, encarando os dilemas de escolha que se oferecem, a cada momento, à sociedade, o que por sua vez favorece a definição de visões convergentes de médio e longo prazo, e também a governança" (Oosterbeek, 2014, p. 188). 
En síntesis, la acción territorial constituye el conjunto de iniciativas que los actores ponen en marcha para construir y dar sentido a un territorio, estas acciones son situadas en un espacio determinado, un espacio de interacción (territorio de acción) incluido dentro de un contexto estructurante más amplio (territorios y sociedades que los abarcan y contienen) y están estructuradas bajo un modelo de gobernanza, condicionadas por las normas o reglas formales e informales vigentes y el intercambio de recursos, que se caracterizan por ser escasos y estar inequitativamente distribuidos (Manzanal \& Ponce, 2012).

Desde esta perspectiva conceptual, a través de esta investigación se analiza la acción territorial generada por los municipios, las acciones que estos llevan adelante para construir el desarrollo de sus propios territorios, bajo el supuesto que las acciones territoriales de estos son estructurantes del futuro. Sin embargo, debe quedar claro que en este trabajo no se analiza todo el conjunto de la acción territorial que tiene lugar en los municipios o distritos, pues esto involucra también a otros múltiples actores, como al sector privado (empresas, productores agropecuarios, artesanos, etc.) y los actores colectivos (organizaciones sociales, organizaciones productivas, etc.), los cuales no constituyen el objeto de análisis de esta investigación.

\section{ETAPAS DE INVESTIGACIÓN Y ANÁLISIS}

Desde el punto de vista metodológico, el análisis y la validación de la hipótesis propuesta se realizó en tres etapas.

En primer lugar se realizó una encuesta muy sencilla a nivel nacional a los intendentes y equipos de gobierno municipal en todos los municipios del país (250 encuestas) (ver encuesta en Anexo). Dicha encuesta relevó información sobre las características generales de los municipios, de los intendentes, de la forma de gestión y de las acciones que los Municipios ponen en marcha en sus territorios. La información proveniente de dicha encuesta fue sistematizada, codificada y cargada en una base de datos y a partir de allí toda esta información fue procesada por un software estadístico y en un Sistema de Información Geográfico lo cual permitió generar tablas, gráficos y mapas de diverso tipo. Dentro de esta encuesta aparecen las siguientes preguntas claves:

- Pregunta 6: Principales problemas de los Municipios.

- Pregunta 14: Principales iniciativas llevadas a cabo para generar dinámicas de desarrollo.

- Pregunta 16: Principales acciones que se llevan a cabo en el Distrito para reducir la pobreza).

Estas preguntas, que constituyen las tres principales variables de análisis, dieron lugar a múltiples respuestas que fueron organizadas en 8 categorías de manera de facilitar el procesamiento.

En segundo lugar, a partir de esta información se realizó un análisis de clasificación con el objetivo de identificar diferentes tipos de acción territorial, para ello se utilizaron dos variables claves: el tipo de iniciativas que lleva adelante la Municipalidad para promover el desarrollo y las iniciativas específicas para reducir la pobreza, esto se justifica porque el principal problema mencionado por los municipios era la pobreza, y la cifra de Necesidades Básicas Insatisfechas que se disponía lo ratificaba. La clasificación y la creación de una tipología de municipios se realizó mediante el Método de Ward de manera de lograr estratos con Distritos lo más homogéneos posibles entre ellos y lo más 
heterogéneos posible en relación a los demás. Una explicación detallada de esta metodología se plantea posteriormente.

En tercer lugar, y con la tipología de municipios ya establecida, se realizaron 20 entrevistas en base a un guion predeterminado a Intendentes de municipios representativos de cada una de estas categorías, de manera de poder realizar un análisis y una caracterización en profundidad de cada una de ellas. Estas entrevistas se realizaron teniendo en cuenta la metodología de "análisis estratégico", inspirado en Crozier y Friedberg (1977), lo cual permitió comprender la relación que se establece entre el sistema (contexto territorial que define la libertad del actor, así como la racionalidad que puede emplear éste en su acción), y el actor propiamente dicho (el intendente), que es el que genera las acciones. Así, tal como lo plantea Crozier y Friedberg (1977):

"el análisis estratégico está obligado a reconocer y a asumir la contingencia irreductible del fenómeno que está en estudio, forzosamente tiene que adoptar un procedimiento hipotético-inductivo.......un procedimiento que se sirve de la experiencia vivida de los participantes para proponer y verificar las hipótesis cada vez más generales sobre las características del conjunto" (Crozier \& Friedberg, 1977, pp. 369-370).

Bajo este marco teórico metodológico se entiende que el Municipio desarrolla comportamientos racionales, pero esa racionalidad es un constante juego conducido en el que se encuentran presentes los recursos que el Municipio controla (recursos económicos, humanos y simbólicos), y las presiones del sistema que se expresa no sólo en las crecientes demandas sociales, sino también en el aumento de las responsabilidades derivadas de los procesos de descentralización de las últimas décadas.

\section{EL MUNICIPIO, UNIDAD FUNDAMENTAL DE ORGANIZACIÓN TERRITORIAL}

Paraguay es un país de medianas dimensiones, con una superficie de $406.752 \mathrm{kms}^{2}$, localizado en un área de transición y con una posición estratégica en el contexto de América del Sur. Desde el punto de vista de su organización político administrativa, el territorio se divide en la capital (Asunción) y 17 Departamentos, estos a su vez están divididos en distritos o Municipalidades que suman un total de 254, algunos de ellos de muy reciente creación. Estos distritos o Municipalidades son las unidades fundamentales de la organización territorial, pues tienen una administración propia (El Municipio), abarcando una zona urbana y otra rural, en muchos casos el área urbana se vuelve a dividir en localidades y en barrios, en tanto las áreas rurales se dividen en pequeños asentamientos denominados colonias o compañías (figura 1). 


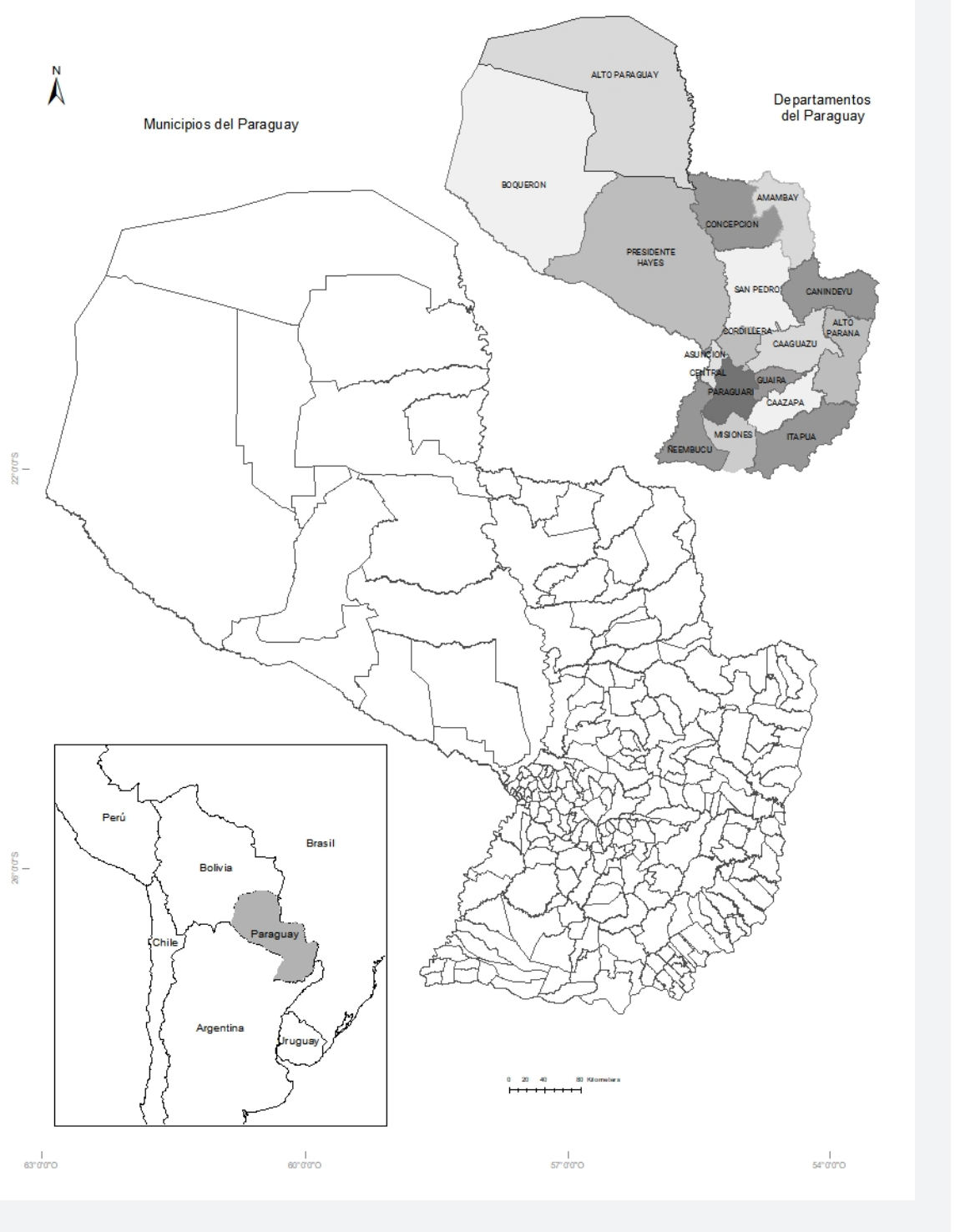

Fuente: Elaborado por el autor con base en el mapa oficial de la Dirección del Servicio Geográfico Militar del Paraguay.

Las características geográficas del país y el modelo histórico de poblamiento y organización territorial han definido Municipios muy diferentes en términos de población y superficie, lo cual torna más compleja la administración territorial del país. Coexisten en el Paraguay Municipios de la zona rural que tienen menos de $10 \mathrm{~km}^{2}$., hasta otros que, en la zona occidental o chaco tienen más de $50.000 \mathrm{kms}^{2}$. La Tabla 1 da cuenta de estas profundas diferencias en términos de superficie y población entre Municipios. 
TABLA 1

ESTRATOS DE POBLACIÓN DE LOS MUNICIPIOS DEL PARAGUAY

\begin{tabular}{|c|c|c|c|c|c|c|c|}
\hline Grupos de Población & $\begin{array}{l}\text { Cantidad de } \\
\text { Municipios }\end{array}$ & Habitantes & $\begin{array}{c}\% \text { de } \\
\text { habitantes }\end{array}$ & $\begin{array}{c}\text { Superficie } \\
\text { (Km2) }\end{array}$ & $\begin{array}{c}\% \text { de } \\
\text { Superficie }\end{array}$ & $\mathrm{H} / \mathrm{S}$ & MEDIA POBLACIONAL \\
\hline $1^{0}$ Más de 300.000 & 1 & 525.294 & 7,7 & 128 & 0,03 & 4.104 & 525.294 \\
\hline $\begin{array}{l}2^{0} 100.001 \mathrm{a} \\
300.000\end{array}$ & 13 & 2.210 .951 & 32,3 & 7.573 & 1,9 & 292 & 170.073 \\
\hline $3^{\circ} 50.001$ a 100.000 & 16 & 1.112 .361 & 16,2 & 9.625 & 2,4 & 116 & 69.523 \\
\hline $4^{0} 20.001$ a 50.000 & 50 & 1.479 .908 & 21,6 & 145.171 & 35,7 & 10 & 29.598 \\
\hline $5^{0} 10.001$ a 20.000 & 61 & 882.742 & 12,9 & 70.755 & 17,4 & 12 & 14.471 \\
\hline $6^{\circ}$ Hasta 10.000 & 109 & 643.270 & 9,4 & 166.740 & 41,0 & 4 & 5.902 \\
\hline Error de cálculo & & & & 6.760 & 1,7 & & \\
\hline Total & 250 & 6.854 .526 & 100 & 406.752 & 100,0 & 17 & 27.418 \\
\hline
\end{tabular}

Fuente: Elaborado por el autor con base en la Dirección General de Estadísticas, Encuestas y Censos (DGEEC, 2015).

De acuerdo a los datos de la tabla anterior, el $40 \%$ del territorio del país está ocupado por Municipios que sólo tienen el 9,4\% de la población, en tanto en el extremo contrario, el $40 \%$ de la población del país ocupa menos del $2 \%$ de la superficie del país. Desde el punto de vista demográfico, la capital Asunción con medio millón de habitantes, constituye un caso singular, pues reúne el 7,7\% de la población del país. El segundo grupo de 13 municipios con una población entre 100 mil y 300 mil habitantes (170.000 de promedio) tienen el 32,3\% de la población del país. Los 16 municipios siguientes, con una población de 50 a 100 mil habitantes (69.523 de promedio), tienen el 16,2\% de la población. Los siguientes 50 municipios con 20 a 50 mil habitantes (30 mil habitantes promedio) tienen el 21,6\% de la población total. Los últimos dos grupos en tamaño de población con 10 mil a 20 mil habitantes (14.471 de promedio), y el de menos de 10 mil (5.902 de promedio), tienen juntos el 22,3\% de la población.

La administración del municipio está a cargo de los gobiernos municipales, cuya estructura está definida por la Constitución Nacional, por la Ley Orgánica Municipal (3.966/2010). La autonomía municipal está garantizada a partir de la Constitución de 1992, ya que le otorga a la población distrital el derecho de nombrar a sus propias autoridades, y al gobierno municipal de recabar tributos: impuestos inmobiliarios, urbanos y rurales, más las tasas y contribuciones pertinentes, es decir que el Municipio tiene autonomía en la recaudación y uso de los recursos propios, además de los recursos transferidos por el Gobierno Nacional y Departamental.

Los cargos electivos del Municipio son el Intendente Municipal y los Concejales quienes integran la Junta Municipal. En el caso del Paraguay, el 89\% de los intendentes son hombres (223), en tanto solo 27 son mujeres; en términos de edad, los intendentes son personas que tienen mayormente entre 41 y 50 años de edad (34,4\%), y en segundo lugar los que tienen entre 31 y 40 años de 
edad (31,6\%). En tercer lugar, los que tienen entre 51 y 60 años de edad (21,6\%). En términos de formación, el 4,4\% de los Municipios tienen intendentes con estudios primarios terminados, el $35.9 \%$ terminó sus estudios secundarios, el 14,4\% tiene estudios post secundarios y el $45 \%$ tienen estudios universitarios terminados.

Con el fin de cumplir sus fines y promover la participación de la ciudadanía, las autoridades municipalidades organizan otras formas de organización política previstas en la ley como las Juntas Comunales de Vecinos y las Comisiones Vecinales que representan vecindarios y promueven la participación popular. Los municipios cuentan además con Juzgados de Faltas Municipales designados por las Juntas Municipales para aplicar sanciones.

\section{PROBLEMÁTICAS DEL TERRITORIO Y ACCIÓN MUNICIPAL}

Las problemáticas de los Distritos en la vasta geografía paraguaya son muy dispares y dependen de cuestiones estructurales, claramente señaladas en numerosos diagnósticos territoriales, sociales y económicos del país, y que se vinculan a las condiciones ambientales, la carencia de infraestructuras, la falta de capital e inversiones productivas, la heterogeneidad de los sistemas de producción, la pobreza, el deterioro del hábitat y el espacio construido, etc. (Cabello \& Vázquez Aranda, 2013; Giménez, 2010). Sin embargo, tal como se planteó anteriormente, no sólo interesa comprender estos problemas "objetivos", sino la percepción y la representación que los intendentes y sus equipos de gestión municipal tienen sobre su propia realidad, pues, es a partir de estas representaciones que se construyen las políticas y las acciones para el desarrollo. Así, tal como lo plantea Crozier y Friedberg (1977, p. 377).

"A través de las actitudes se perciben los valores de los individuos. La actitud constituye el puente entre las conductas observables de los individuos por una parte (las acciones) y la estructura de valores que las orienta, de por sí inobservables, por otra. Es a través de las actitudes de los actores (en nuestro caso los intendentes) que se pueden observar sus objetivos. En el análisis estratégico lo que explica las actitudes y lo que se pretende alcanzar mediante ellas es el estado de un sistema de acción y la manera en que sus características y su modo de regulación estructura los juegos en lo que los miembros deben jugar" (Crozier \& Friedberg, 1977, p. 384).

Teniendo en cuenta esta premisa metodológica, los problemas más importantes percibidos por los intendentes es la pobreza, el desempleo y la desintegración social, y en segundo lugar la falta de caminos (Tabla 2). Más del 60\% de los intendentes del país colocan a estos temas como los más problemáticos de los Distritos del país. En tercer lugar aparece la carencia y el deterioro de los equipamientos y servicios públicos. Estos tres primeros tópicos suman el $76 \%$ de la problemática vista por los alcaldes municipales. El anexo 2 presenta una recopilación de algunas de las respuestas planteadas por los encuestados. 
TABLA 2 LOS PRINCIPALES PROBLEMAS DE LOS MUNICIPIOS PERCIBIDOS POR SUS INTENDENTES

\begin{tabular}{lcc} 
Problemas & Frecuencia & (\%) \\
\hline Total & 250 & 100,0 \\
Pobreza, desempleo y desintegración social & 78 & 31,2 \\
Caminos & 35 & 30,8 \\
Carencias y deterioros en los equipamientos y servicios públicos & 18 & 14,0 \\
Degradación del hábitat y el ambiente & 14 & 7,2 \\
Carencia de infraestructuras básicas & 5,6 \\
Debilidad institucional de los Municipios & 12 & 4,8 \\
Violencia e inseguridad & 10 & 4,0 \\
Otros ${ }^{1 /}$ & & 6 \\
\end{tabular}

Fuente: Elaborado por el autor con base en la Encuesta de Gestión de Desarrollo Local (2016).

Nota: 1/ Incluye: Bajo nivel de desarrollo integral de la agricultura familiar, no tiene problemas en su comunidad.

Otros problemas referenciados por los intendentes son la degradación del hábitat y el ambiente, la carencia de infraestructuras básicas (agua, saneamiento), la debilidad institucional de los municipios y la violencia e inseguridad, especialmente en los Municipios más grandes. Es claro que estas problemáticas identificadas por los intendentes y sus equipos técnicos no son sólo problemas imaginados, sino emergentes de una realidad estructural que tiene datos e indicadores que permiten validarlos.

A partir de la identificación de los problemas locales visto desde la mirada de los intendentes, estos ponen en marcha acciones para superar los mismos (Tabla 3). De acuerdo a la encuesta nacional aparece un conjunto muy vasto de acciones las cuales han sido reagrupadas en grandes categorías. La principal iniciativa que llevan adelante las Municipalidades es la mejora de los caminos y de los sistemas de transporte en general, en segundo lugar la promoción para la inversión y el desarrollo productivo en general, y en tercer lugar la gestión político institucional como mecanismo para la obtención de recursos, o para la organización de la sociedad local. Estos tres primeros tópicos sintetizan para ellos el 71\% de su gestión. En cuarto lugar aparece la planificación y la gestión territorial y ambiental, la creación y mejora de equipamientos y servicios públicos y el fortalecimiento de la participación social y la vida comunitaria. El anexo 2 presenta una recopilación de algunas de las respuestas planteadas por los encuestados. 
TABLA $3 \quad$ PRINCIPALES ACCIONES EMPRENDIDAS POR LOS MUNICIPIOS

\begin{tabular}{|c|c|c|}
\hline Iniciativas & Frecuencia & (\%) \\
\hline Total & 250 & 100,0 \\
\hline Mejora de caminos y sistemas de transporte & 78 & 31,2 \\
\hline Promoción para la inversión y desarrollo productivo & 68 & 27,2 \\
\hline Gestión político- institucional & 31 & 12,4 \\
\hline Planificación y gestión territorial y ambiental & 21 & 8,4 \\
\hline Creación y mejora de equipamientos y servicios públicos & 20 & 8,0 \\
\hline Fortalecimiento de la participación social y la vida comunitaria & 14 & 5,6 \\
\hline Otros ${ }^{1 /}$ & 11 & 4,4 \\
\hline No disponible & 7 & 2,8 \\
\hline
\end{tabular}

Fuente: Elaborado por el autor con base en la Encuesta de Gestión de Desarrollo Local (2016).

Nota: 1/ Incluye: Asistencia a la ciudadanía, creación de infraestructura.

Más allá de los problemas percibidos por intendentes y de las acciones puestas en marcha para resolverlos, otro análisis complementario fue la identificación de las acciones que realizan los municipios para reducir específicamente las situaciones de pobreza. En efecto, la pobreza es un problema clave en Paraguay, pero no sólo desde una perspectiva de ingresos, sino desde una perspectiva multidimensional que afecta a todos los municipios del país en mayor o menor medida. La respuesta que los municipios dan a esta problemática es muy dispar y depende de la mirada que los intendentes tiene sobre la pobreza y sobre sus criterios y posturas ideológicas acerca de cómo superar la misma. En efecto, la mirada sobre la pobreza y las consecuencias que ello tiene ha cambiado notablemente en las últimas décadas, lentamente Paraguay (y sus funcionarios gubernamentales) ha ido cambiando la mirada en torno de la pobreza, de una mirada centrada en los ingresos, de relativa facilidad para su cuantificación y análisis, se está pasando a una concepción de la pobreza mucho más multidimensional, que considera que las causas de la pobreza no son sólo la falta de ingresos, sino la carencia de caminos (un problema de suma importancia en las áreas rurales del Paraguay, donde las condiciones meteorológicas limitan la conectividad y por lo tanto el acceso de la población a múltiples servicios), la accesibilidad a servicios educativos y sanitarios, y el acceso a otros bienes personales. Esta multidimensionalidad de la pobreza es medida actualmente a través del Índice de Pobreza Muldimensional (IPM) el cual incluye un conjunto de 10 indicadores organizados en tres grandes categorías: educación (años de escolarización, niños escolarizados), salud (mortalidad infantil, nutrición) y el nivel de vida (disponibilidad de electricidad, saneamiento, agua potable, suelo, combustible del hogar y bienes varios). Según datos del Informe de Desarrollo Humano del PNUD (Programa de las Naciones Unidas para el Desarrollo) y del OPHI (Oxford Poverty \& 
Human Development Initiative) Paraguay tiene un Índice de pobreza multidimensional del 0,064, encontrándose en el lugar número 44 de un conjunto de 104 países (desde el $1^{\circ}$ menos pobre hasta el $104^{\circ}$ el más pobre), ubicándose en el lugar no 15 dentro del contexto de América Latina, sobre un total de 32 países, es decir en una situación media dentro del continente.

Frente a esta consideración de la pobreza como un hecho multidimensional, la mayor parte de los municipios entiende que la superación de la pobreza se debe hacer a través de una mejora de la producción agrícola, ya sea para el autoconsumo o para el mercado, para lo cual el municipio entrega semillas, realiza el laboreo de las parcelas de los productores, etc.; y en segundo lugar se intenta reducir la pobreza a través de gestiones ante el gobierno central para viabilizar el acceso de la población a programas sociales nacionales y muy especialmente al Tekoporâ (Programa de asistencia...). En tercer lugar muchos municipios consideran que una forma de reducir la pobreza es a través de la asistencia ciudadana, que implica la entrega de material de construcción, una ayuda específica en temas de salud, o la entrega de alimentos entre otros, todos ellos elementos más propios de una política asistencialista. Las iniciativas que teóricamente aparecen como más promotoras del desarrollo humano o más estructurales, como son la capacitación, la provisión de servicios básicos, la construcción de viviendas y la mejora de caminos, aparecen rezagadas con no más del 23\%. La Tabla 4 presenta el detalle de estas acciones de lucha contra la pobreza, en tanto que el anexo 2 presenta una recopilación de algunas de las respuestas planteadas por los encuestados.

\section{TABLA 4 PRINCIPALES ACCIONES DE LUCHA CONTRA LA POBREZA EMPRENDIDAS POR LOS MUNICIPIOS}

$\begin{array}{lcc}\text { Acciones para reducir la pobreza } & \text { Frecuencia } & 1 \% \text { ) } \\ \text { Total } & 250,0 & 26,0 \\ \text { Apoyo a la producción agrícola } & 63 & 25,2 \\ \text { Acceso a Tekoporâ y otros planes sociales } & 37 & 14,8 \\ \text { Asistencia Ciudadana (entrega de materiales, de dinero u otros apoyos directos) } & 29 & 11,6 \\ \text { Otros }{ }^{1 /} & 18 & 7,2 \\ \text { Capacitaciones } & 15 \\ \text { Provisión de servicios básicos } & 12 & 6,0 \\ \text { Construcción de viviendas y acceso a terrenos } & 11 & 4,8\end{array}$

Fuente: Elaborado por el autor con base en la Encuesta de Gestión de Desarrollo Local (2016).

Nota: ${ }^{1 /}$ Incluye: Fortalecimiento de la participación ciudadana, asistencia en salud. 


\section{TIPOS, ESTILOS Y LÓGICAS DE LA ACCIÓN TERRITORIAL}

La combinación de las acciones puestas en marcha para promover el desarrollo y para reducir la pobreza define estilos y lógicas de acción territorial por parte de los municipios. No son iguales los gobiernos locales que centran sus acciones en crear infraestructuras por ejemplo, que aquellos otros que centran sus acciones en la asistencia social, o aquellos que se concentran en promover el desarrollo productivo. Teniendo en cuenta esta premisa, a partir de esta investigación se construyó una tipología de municipios según su lógica y modalidad de acción territorial, sobre la base o combinación de dos grandes variables de análisis:

- Principales iniciativas llevadas a cabo en el Distrito para generar dinámicas de desarrollo y;

- Principales acciones que se llevan a cabo en el Distrito para reducir la pobreza.

Estas dos grandes variables se plantearon como preguntas en la encuesta nacional y dieron varias respuestas posibles. Son estas variables con sus respuestas o declinaciones posibles lo que constituyen el objeto de análisis de este trabajo. Futuras investigaciones deberán permitir cruzar estas variables con otras como son el nivel de formación de los intendentes, el nivel de pobreza del Municipio, la cantidad de habitantes, etc. pudiendo generar nuevos hallazgos y conocimientos de importancia crítica para el diseño de políticas de desarrollo.

Una vez determinada las variables se dispone entonces de una matriz reducida de 2 variables $\mathrm{x}$ 250 municipios del Paraguay. Se procede a la aplicación del método de conglomeración jerárquica, para el cual existen distintas metodologías de agrupación. En este caso el método de clasificación empleado es de tipo jerárquico ascendente, en concreto mediante el procedimiento de Ward o de mínima pérdida de inercia. Este método de Ward implica una estrategia de unión de individuos en cluster a través de un procedimiento jerárquico, en el cual en cada etapa de aglomeración se unen dos individuos para los cuales se tienen mínimas diferencias con respecto al centroide del Cluster, es decir que se busca a través de este método que los conglomerados se constituyan de tal manera que, al fundirse o unirse dos individuos, la pérdida de información producto de esta fusión fuese mínima. Tal como lo expresa Ward (1963, p. 236):

"Situations often arise in which it is desirable to cluster large numbers of objects, symbols, or persons into smaller numbers of mutually exclusive groups, each having members that are as much alike as possible. Grouping in this manner makes it easier to consider and understand relations in large collections; hence it often increases efficiency of management. Grouping, however, ordinarily results in some loss of information that may be quantified in a "value-reflecting" number" (Ward, 163, p. 236).

La cantidad de clusters que se generó se planteo en función de la evaluación que se hizo de los coeficientes de la tabla de aglomeración, la cual indica la cantidad óptima de clusters. En base a los valores obtenidos, y la evaluación de las diferencias en los coeficientes se procede a la selección de 4 cluster o tipos de municipios según sus iniciativas generales y de lucha contra la pobreza. El anexo 3 presenta el gráfico surgido de este análisis de cluster. Este tipo de categoría de municipios se describen a continuación: 


\subsection{Tipo I: municipios promotores del desarrollo y la asistencia local urbana}

El carácter distintivo de estas 49 municipalidades es que actúan promoviendo el desarrollo a través de las mejoras en el sistema vial (pavimentación o empedrado de caminos rurales) y el ordenamiento territorial a través de planes de uso del suelo y de mejora del paisaje, es decir, son acciones de inversión en infraestructura y regulación territorial. En la lucha contra la pobreza el municipio tiene autonomía, es decir que tiene sus propias iniciativas de asistencia ciudadana a través de la entrega servicios y bienes a las familias más pobres (bolsones de comida, útiles escolares para los niños), como la provisión de servicios y bienes comunales ordinarios (ayuda económica para el pago de los servicios de luz) hasta la provisión de gastos de emergencias de la familia, como ser los decesos (entregan a la familia el cajón y pagan la sepultura del familiar muerto) y situaciones de empobrecimiento catastrófico por motivos de gastos de salud. No dependen de la intermediación o ejecución de actividades del Gobierno central ni de las Gobernaciones como son las actividades de asistencia condicionada (Tekoporâ - Adultos mayores). Frecuentemente se trata de comunas prósperas, con una organización y gobernabilidad local más consolidada y con menores reclamos de asistencia a la extrema pobreza.

Estos municipios tienen una media poblacional mayor que el promedio, 47.218 habitantes, cuando el promedio nacional es de 27.418 habitantes por comuna. Presentan una dinámica de crecimiento poblacional alta, con 1,6\% anual, en tanto la media nacional es de 1,4\%. Son zonas receptivas de población. Por otro lado son los que tienen la menor proporción de NBI (necesidad básica insatisfecha $)^{1}$, con un $51 \%$ de hogares con por lo menos una NBI insatisfecha, en tanto la media nacional es de $55 \%$.

Ejemplos son San Bernardino, San Cosme y Damián, Caaguazú, San Juan Bautista, Capiatá, Itaguá, Lambaré, San Loreto. Un caso a resaltar de este tipo de municipalidades es la Capital, Asunción que tiene una Dirección de Desarrollo Social, escuelas municipales, atención a la infancia y la juventud, cuidado en eventos climáticos (inundaciones), etc.

\subsection{Tipo 2: municipios con gestión de redes}

El carácter distintivo de estas 40 municipalidades es la construcción de redes político-institucionales de varios niveles escalares (local, departamental, nacional e internacional) para obtener recursos y asistencia para su desarrollo. Así, dentro de este contexto los intendentes se consideran articuladores y promotores de sus territorios ante otros organismos y actores políticos o empresariales, es decir que tienen fuertes contactos políticos a nivel Departamental o principalmente nacional en los diferentes Ministerios, a donde acuden para negociar recursos para sus Municipios. Un claro ejemplo de esta lógica de funcionamiento son las iniciativas de reducción de la pobreza, no hay políticas autónomas ni de origen local, sino que todo lo que se hace a nivel local para reducir o paliar la pobreza depende de la utilización de recursos provenientes de las transferencias condicionadas y los programas de Fomento de la agricultura del gobierno central, es decir de otras redes y actores de los cuales obtienen recursos. Son municipios sojeros, ganaderos o industriales, el fomento productivo queda en manos de

\footnotetext{
${ }^{1}$ Las necesidades básicas insatisfechas no son únicamente un problema de los hogares, sino de la cobertura estatal existente, pues hay por ejemplo zonas rurales prosperas pero con escuelas y servicios médicos lejanos, sin saneamiento ni agua potable compartida, lo cual limita por su alto costo la cobertura general, generando indicadores de NBI más elevados que en las zonas urbanas de mayor densidad y por ende de menores costos de prestación de servicios.
} 
las empresas locales y de otros actores territoriales. En estos territorios la expansión de la educación superior (captando Universidades para que se asienten en el Distrito), las redes de carreteras y la logística (mejora de las rutas y pavimentación, localización de empresas de transporte, etc.) son temas claves.

Estos municipios tiene mayor tamaño poblacional que la media nacional, con 36.643 habitantes, con un fuerte incremento poblacional anual (1.6\%). Las NBI son un poco inferiores a la media nacional, con 53\% de hogares con al menos una necesidad insatisfecha.

Son claro ejemplo de este tipo de municipios Concepción en el norte de la región oriental, Villarrica en el Centro de la región oriental y también Loma Plata, una comuna exitosa con predominancia de población menonita, y algunas de predominio de población inmigrante reciente procedente del Brasil "brasiguayos", como Santa Rita, o el satélite próspero de Ciudad del Este, Minga Guazú, o el de población con influencia eslava como Fram. Este no es un grupo homogéneo, ni sus municipios tienen una misma historia, ya que, por un lado incluye a municipios nuevos, con incidencia de inmigración más reciente, que nacieron a finales del siglo XX, como Loma Plata o Fram, y, por otro lado, municipios centenarios como Concepción o Villarrica, que, habiéndose rezagado un tiempo en su dinámica de desarrollo, se dinamizaron en las últimas décadas, apostando a su capital social y simbólico.

\subsection{Tipo 3: municipios creadores de infraestructura y promotores del capital humano y social}

Son cuarenta municipios que se destacan por tener una visión más integral del desarrollo, que ponen el acento en la mejora de los caminos rurales y la promoción del desarrollo productivo a través de alianzas con el Ministerio de Agricultura y con programas de desarrollo rural de financiamiento internacional (especialmente el Fondo Internacional de Desarrollo agrícola y el Banco Mundial), con quienes llevan adelante estrategias locales de acompañamiento a los productores agropecuarios. La reducción de la pobreza no pasa por la asistencia social clásica (reparto y distribución de bolsones de comida, entrega de dinero, etc.), propia o dependiente del gobierno nacional, sino por iniciativas de formación de capital humano y social, centradas en la capacitación de las personas a través de cursos y ofertas de formación, y la provisión de servicios básicos como agua, luz, servicios de salud, etc. que permitan una mejora real de la calidad de vida. Así, la reducción de la pobreza es entendida como una política de promoción socioeconómica y no como parte de una lógica política de carácter más clientelar.

Son zonas con un empresariado muy influyente. El paradigma sobre las cuales se sustentan estas municipalidades es la modernidad empresarial, la generación de nueva riqueza, la confianza en el mercado y en la dinámica de los capitales. Se encuentran por lo general en zonas de economía agroexportadora o de producción de energía, como Ciudad del Este y Pedro Juan Caballero, Ayolas y Filadelfia, incluyendo también ciudades con mayor crecimiento demográfico del departamento central como Luque, Guarambaré o Augusto Saldívar, en donde junto al desarrollo empresarial, hay un proceso de urbanización acelerada y la mutación de la agricultura familiar campesina, ahora orientada hacia el mercado interno urbano (rubros frutícolas, hortícolas y de ganado menor).

En líneas generales estos municipios tienen menos población que la media, 21.336 habitantes en promedio, pero con una fuerte dinámica de crecimiento poblacional ( $1,7 \%$ anual), y con problemas severos de exclusión con el 57\% de los hogares con alguna NBI. Los más vulnerables son la población indígena, la campesina criolla y los nuevos migrantes que se instalan en áreas con poca infraestructura instalada. 


\subsection{Tipo 4: municipios promotores de la competitividad económica}

Este es el grupo más vasto con 121 municipios, si aparentemente aparece como un conjunto múltiple y heterogéneo de municipios, visto en detalle debe ser considerado como el tipo de municipios más representativo de la tensión entre un modelo tradicional y un modelo promotor de municipio. Estos municipios se encuentran en territorios donde se manifiesta una dualidad entre una sociedad empresarial y una sociedad tradicional familiar. De allí que el gran desafío de estas municipalidades es lograr un aumento de competitividad y desarrollo productivo y de empleo, que asegure la cohesión social.

El objetivo general y más evidente en todos estos municipios es mejorar las condiciones de producción y empleo, especialmente de su población campesina e indígena, para lo cual generan múltiples y diversas iniciativas para el desarrollo productivo (especialmente con alianzas con el Ministerio de Agricultura y con los organismos de cooperación bilateral -Japón, Taiwan, Alemania, Italia, entre otros, y con los programas de desarrollo rural de los organismos multilaterales de crédito Banco Interamericano de Desarrollo y Banco Mundial). También son municipios que se empeñan en el fomento de las inversiones, intentando atraer empresas o cooperativas para que desarrollen actividades en su territorio. Las iniciativas de mejora del sistema vial a través del empedrado de caminos vecinales es también un elemento clave. Por otro lado las iniciativas para reducir la pobreza no dependen de sus propios recursos, sino que se limitan a canalizar los recursos del gobierno nacional, a organizar la demanda local de planes sociales (Tekoporâ) y a apoyar a la producción agrícola de los sectores rurales más pobres. Es decir que las iniciativas para reducir la pobreza no son parte de la agenda autónoma del Municipio, sino de la agenda del gobierno nacional a través de sus diferentes ministerios.

Estas son las comunas más pequeñas y más numerosas, con 18.361 habitantes en promedio y con la menor tasa de crecimiento poblacional (1,2\% anual). Si bien la población rural tiene un ritmo de expansión menor que la dinámica urbana, su descenso se encuentra amortiguado por una fuerte cultura y tradición rural, que en parte se mantiene y en parte se moderniza gracias al desarrollo de las comunicaciones y el transporte. Por otro lado las NBI en estos municipios son superior a la media, con un $57 \%$.

Casos paradigmáticos de estos municipios son los casos de Encarnación, con zonas pobres y ricas en contraste. Piribebuy y Caacupé, a caballo entre la sociedad tradicional y la expansión empresarial, Curuguaty donde la frontera de modelos productivos generó fuertes tensiones y Paraguarí, una sociedad conservadora que se moderniza con difícil integración.

Frente a este tipo de acciones llevadas a cabo por parte de los diferentes tipos de Municipios, el Gobierno Nacional o los gobiernos departamentales permanecen inertes, es decir, apoyan todas las iniciativas posibles, pero no tienen ningún tipo de política clara ni premeditada de orientación de las acciones, es decir que cada tipo de municipio avanza en acciones posibles, sin una clara definición de cuál es el horizonte a seguir ni las mejores estrategias posibles para promover el desarrollo y reducir la pobreza. Se podría afirmar sin lugar a dudas que esta categoría de municipios, y cada uno de los tipos de municipios son en definitiva una muestra de la incapacidad estructural del gobierno nacional de conducir el proceso de desarrollo territorial en el país, dejando que todos ellos avancen a prueba y error.

La tabla siguiente (Tabla 5) da cuenta de cada uno de estos tipos de Municipios. En la misma se presentan cada uno de los aglomerados con sus dos grandes variables y las subcategorías que provienen de las respuestas de las encuestas y que han sido sistematizadas. La tabla presenta las frecuencias de las respuestas de las dos variables. 


\begin{tabular}{|c|c|c|c|c|c|}
\hline & & \multicolumn{4}{|c|}{ Estratificación (Ward Método) de acuerdo a la acción municipal predominante } \\
\hline & & $\begin{array}{l}\text { Tipo I: Promoción } \\
\text { del desarrollo y } \\
\text { asistencia local } \\
\text { urbana }\end{array}$ & $\begin{array}{l}\text { Tipo II: Gestión de } \\
\text { redes y desarrollo } \\
\text { rural }\end{array}$ & $\begin{array}{l}\text { Tipo III } \\
\text { Infraestructura, } \\
\text { capital humano y } \\
\text { social }\end{array}$ & $\begin{array}{c}\text { Tipo IV: } \\
\text { Competitividad } \\
\text { económica y } \\
\text { desarrollo rural }\end{array}$ \\
\hline \multirow{12}{*}{$\begin{array}{l}\text { Principal } \\
\text { Iniciativa } \\
\text { llevada a } \\
\text { cabo por la } \\
\text { Municipalidad } \\
\text { para el } \\
\text { desarrollo }\end{array}$} & $\begin{array}{l}\text { Mejora de caminos y } \\
\text { sistemas de transporte }\end{array}$ & $34,70 \%$ & $0,00 \%$ & $27,50 \%$ & $41,30 \%$ \\
\hline & $\begin{array}{l}\text { Promoción para la inversión } \\
\text { y desarrollo productivo }\end{array}$ & $34,70 \%$ & $0,00 \%$ & $30,00 \%$ & $32,20 \%$ \\
\hline & $\begin{array}{l}\text { Gestión político- } \\
\text { institucional }\end{array}$ & $0,00 \%$ & $67,50 \%$ & $10,00 \%$ & $0,00 \%$ \\
\hline & $\begin{array}{l}\text { Planificación y gestión } \\
\text { territorial y ambiental }\end{array}$ & $14,30 \%$ & $0,00 \%$ & $7,50 \%$ & $9,10 \%$ \\
\hline & $\begin{array}{l}\text { Fortalecimiento de la } \\
\text { participación social y la } \\
\text { vida comunitaria }\end{array}$ & $0,00 \%$ & $15,00 \%$ & $12,50 \%$ & $2,50 \%$ \\
\hline & $\begin{array}{l}\text { Creación y mejora de } \\
\text { equipamientos y servicios } \\
\text { públicos }\end{array}$ & $12,20 \%$ & $0,00 \%$ & $5,00 \%$ & $9,90 \%$ \\
\hline & Asistencia a la ciudadanía & $2,00 \%$ & $0,00 \%$ & $5,00 \%$ & $3,30 \%$ \\
\hline & Creación de infraestructura & $2,00 \%$ & $0,00 \%$ & $2,50 \%$ & $1,70 \%$ \\
\hline & NR & $0,00 \%$ & $17,50 \%$ & $0,00 \%$ & $0,00 \%$ \\
\hline & $\begin{array}{l}\text { Apoyo a la producción } \\
\text { agrícola }\end{array}$ & $0,00 \%$ & $37,50 \%$ & $0,00 \%$ & $41,30 \%$ \\
\hline & Asistencia ciudadana & $63,30 \%$ & $15,00 \%$ & $0,00 \%$ & $0,00 \%$ \\
\hline & $\begin{array}{l}\text { Acceso a Tekoporâ y otros } \\
\text { planes sociales }\end{array}$ & $0,00 \%$ & $27,50 \%$ & $0,00 \%$ & $43,00 \%$ \\
\hline \multirow{8}{*}{$\begin{array}{l}\text { Principal } \\
\text { Iniciativa } \\
\text { Ilevada a } \\
\text { cabo la } \\
\text { Municipalidad } \\
\text { para reducir la } \\
\text { pobreza }\end{array}$} & Capacitaciones & $0,00 \%$ & $0,00 \%$ & $45,00 \%$ & $0,00 \%$ \\
\hline & $\begin{array}{l}\text { Provisión de servicios } \\
\text { básicos }\end{array}$ & $0,00 \%$ & $0,00 \%$ & $37,50 \%$ & $0,00 \%$ \\
\hline & Otros & $28,60 \%$ & $7,50 \%$ & $0,00 \%$ & $0,00 \%$ \\
\hline & Mejora de caminos & $0,00 \%$ & $0,00 \%$ & $17,50 \%$ & $3,30 \%$ \\
\hline & $\begin{array}{l}\text { Construcción de viviendas } \\
\text { y acceso a terrenos }\end{array}$ & $0,00 \%$ & $5,00 \%$ & $0,00 \%$ & $8,30 \%$ \\
\hline & Asistencia en salud & $4,10 \%$ & $5,00 \%$ & $0,00 \%$ & $0,00 \%$ \\
\hline & $\begin{array}{l}\text { Fortalecimiento de la } \\
\text { participación ciudadana }\end{array}$ & $4,10 \%$ & $2,50 \%$ & $0,00 \%$ & $0,00 \%$ \\
\hline & Almuerzo escolar & $0,00 \%$ & $0,00 \%$ & $0,00 \%$ & $4,10 \%$ \\
\hline \multicolumn{2}{|c|}{ Recuento (cantidad de municipios) } & 49 & 40 & 40 & 121 \\
\hline
\end{tabular}

Fuente: Elaborado por el autor en base en el procesamiento de la información de la Encuesta de Gestión de Desarrollo Local (2016). 


\section{CONCLUSIÓN}

El desarrollo territorial es la compleja combinación de la acción pública, la acción privada y la acción colectiva (o sociedad civil) que se construye dentro de contextos territoriales, signados en el caso Paraguayo, por los procesos de transformación territorial, el cambio demográfico, la fuerte transformación productiva ligada a la apertura de mercados externos y crecimiento de la empresa rural. Esta combinación de acciones puede dar lugar a dinámicas virtuosas de desarrollo, capaces de contribuir a la superación de la pobreza, la mejora de la calidad de vida, la competitividad económica, la creación de empleos sostenibles y una mejora sustancial de las condiciones ambientales y del hábitat.

En Paraguay, como en el resto de los países de América Latina, estas dinámicas están fuertemente condicionadas por el rol y la presencia del Estado en sus diferentes niveles escalares, tanto de los gobiernos centrales, como subnacionales y en último lugar los gobiernos locales. Mucho se ha analizado y escrito en América Latina sobre el rol de los gobiernos locales y los procesos de descentralización en su relación al desarrollo, muy especialmente durante la década de los 90 , período de fuerte ajuste estructural en la región y de delegación de responsabilidades del gobierno central hacia los gobiernos locales (Aghón \& Cortés, 1998). Este trabajo pretende complementar esta literatura existente, poniendo el énfasis en el análisis de las acciones puestas en marcha por las Municipalidades, partiendo de la hipótesis que las mismas tienen un rol clave y estructurante en el desarrollo territorial del país, aunque no todas tienen las mismas lógicas de funcionamiento y de acción en torno al desarrollo. Varios elementos pueden observarse a partir de este trabajo.

En primer lugar, la diferencia existente entre los municipios en términos de superficie, población y sistemas productivos, los discursos de los intendentes y sus equipos municipales reflejan tres ideas o acuerdos simbólicos sobre el estado de situación de los municipios en el Paraguay:

- La primera de estas representaciones, es que la pobreza es el principal problema del país y de sus municipios. La población es vista como pobre, carente de medios de vida y trabajo; ella es vista a través de la compasión o el miedo por aquellos que han superado esas carencias; o como identidad, ñandeporiahu(nosotros los pobres)poruna mentalidad pre ciudadana que busca arrimarse al más pudiente y entiende que la carencia es fuente derechos.

- La segunda representación es que la naturaleza en parte es inaccesible ( $\sin$ caminos, sin infraestructura). Un territorio de desierto poco habitable, poco apto para el trabajo, poco accesible al mercado y poco compartible comunitariamente por insuficiencia de vías de transporte que permita a la gente apropiarse del mismo y doblegar las distancias para vivir y trabajar juntos. Detrás de esta mirada está la idea de la naturaleza como un adversario hostil o como límite a la convivencia. La interpretación de la naturaleza y del espacio proveniente de la visión precolombina portada por los pueblos originarios, era la de un espacio de vida poblada de espíritus, en imaginarios animistas, un espacio de cacería y recolección. Esta naturaleza cambió a un modelo de capitalismo extractivista aprovechado por pocos actores, claramente vinculados a las corporaciones transnacionales.

- La tercera representación es que hay una carencia del Estado y de servicios públicos. Hay un claro fracaso de la institución estatal para materializar intereses colectivos y proveer soluciones a las necesidades comunes, sea por la carencia de medios y poca recaudación, sea por la falta de un contrato social más incluyente, o por la captura privada de los recursos colectivos. 
En segundo lugar, a partir de estas representaciones sobre el estado de situación del país y de sus municipios, los intendentes y sus equipos técnicos generan acciones para superar estos problemas bajo un ideario de desarrollo que cambia según los contextos geográficos y culturales. Las acciones puestas en marcha son claramente concordantes con las problemáticas percibidas.

En tercer lugar, se puede tipificar a los Municipios según los comportamientos que tienen los mismos frente a sus problemáticas. Es decir que los municipios pueden diferenciarse y clasificarse según sus estilos de intervención o por el tipo de acciones que ponen en marcha para revertir los problemas estructurales y construir procesos de desarrollo territorial según sus opciones y los medios con los que cuentan. Si bien esta tipología constituye una síntesis de dinámicas complejas, envuelve dos grandes dinámicas estructurales de los municipios.

- La dinámica de creación de redes y captación de recursos, acá se observan en líneas generales dos situaciones bien contrapuestas, por un lado municipios que construye $\mathrm{n}$ una red multiescalar para la obtención de recursos y por otro lado municipios con baja capacidad para gerenciar redes, por lo cual se concentran en los recursos endógenos.

- La dinámica de las acciones propiamente dichas, donde se visualizan claramente municipios que se orientan a la creación de infraestructura y equipamiento, municipios que se orientan a la promoción del desarrollo productivo y los municipios que se orientan en la asistencia ciudadana bajo cualquiera de sus formas, o bien, municipios donde sus acciones están sumamente diversificadas. Acá importan los pesos relativos de la modernidad urbana y la rural así como las inercias, relaciones y tradiciones.

Esta tipología de municipios según sus estilos de acción sintetiza el vasto campo de posibilidades de intervención de los municipios, por lo cual esta tipología debe considerarse ante todo como una herramienta para la interpretación de las formas de "construir" el desarrollo local así como de intervenir frente a la realidad. No se trata de una descripción de las características estructurales de los municipios como son su población, superficie, presupuesto, etc.

A partir de esta investigación, otros dos grandes temas aparecen como agenda de futuro. En primer lugar la posibilidad de realizar nuevos cruzamientos de información sobre la base de la encuesta nacional, así, interesaría analizar la relación que tienen estos tipos de municipios con otras variables como son el tipo de estructura municipal, los recursos disponibles, el nivel de conectividad, el nivel de población, etc., pues esto permitiría caracterizar mejor a los municipios y por ende tomar mejores medidas para la promoción y el desarrollo territorial en el país. En segundo lugar, avanzar con nuevos trabajos analíticos permitiría analizar los impactos reales y mensurables que cada uno de estos tipos de municipios tiene en la dinámica y desarrollo territorial en el país, así como para amortiguar los problemas sociales, de manera de poder establecer criterios de fortalecimiento institucional y de promoción del desarrollo más ajustados al estilo y a la vocación de los municipios, y sus condiciones. 


\section{REFERENCIAS}

Aghón, G., \& Cortés, P. (1998). Descentralización y gobiernos municipales en América Latina. In R. Jordan, \& D. Simioni. (Comp.), Ciudades intermedias de América Latina y el Caribe: propuestas para la gestión urbana (pp. 69-106). Vitacura, Santiago de Chile: Comisión Económica para América Latina y el Caribe.

Bustos Cara, R. (2008, mayo). Por una geografía de la acción territorial. In Anales de las 100 Jornadas Cuyanas de Geografía: La geografía frente a la necesidad de integrar territorios y voluntades, Mendoza, Argentina.

Cabello, C., \& Vázquez Aranda, V. I. (2013). Propuestas para un sector productivo competitivo e inclusivo: un instrumento de diálogo y construcción de consensos para el desarrollo rural integral. Asunción, Paraguay: Instituto Desarrollo.

Cámara Paraguaya de Exportadores y Comercializadores de Cereales y Oleaginosas. (2013). Área de siembra, producción y rendimiento. Asunción, Paraguay. Recuperado de http://capeco. org.py/area-de-siembra-produccion-y-rendimiento/

Crozier, M., \& Friedberg, E. (1977). Lacteur et le système: les contraites de l'action colective. Paris, Francia: Points.

De Rubertis, S. (2010). Sviluppo come conflitto. La pianificazione strategica in Puglia. Lecce, Italia: Università del Salento - Coordinamento SIBA.

Dirección General de Estadísticas, Encuestas y Censos. (2015). Población nacional estimada y proyectada, según sexo, departamento, y distrito, 20002025: revisión 2015. Asunción, Paraguay. Recuperado de https://www.dgeec.gov.py/Publicaciones/ Biblioteca/proyeccion $\% 20$ nacional/Proyecciones $\% 20$ Departamentales\%20-\%20final.pdf

Giménez, C. (2009). Situación y perspectivas del sector agro-rural paraguayo. (Serie Sector AgroRural Paraguayo $n^{\circ} 3$ ). Asunción, Paraguay: Instituto Interamericano de Cooperación para la Agricultura. Recuperado de http://repiica.iica.int/docs/B2014e/ B2014e.pdf

Guereña, A. (2011). Derecho a producir. Invertir más y mejor en la pequeña agricultura de América del Sur. Barcelona, España: Intermón Oxfam. Recuperado de https://www-cdn.oxfam.org/ s3fs-public/file_attachments/derechoaproducir_ oxfamcrece-04102011_3.pdf

Lajarge, R. (2011). Le développement territorial ou comment satisfaire le besoin grandissant de territorialités multiples. Paris, Francia: Fonder les Sciences Territoriales. Recuperado de https://halshs. archives-ouvertes.fr/halshs-00700675/document

Manzanal, M., \& Ponce, M. (Org). (2012). La desigualdad ¿del desarrollo? Controversias y disyuntivas del desarrollo rural en el Norte argentino. Buenos Aires, Argentina: Ediciones Ciccus.

Nickson, A., (2016). El gobierno local en el Paraguay, un análisis comparativo a través de diez elementos. Asunción, Paraguay: Investigación para el desarrollo \& Asociación de Juntas Municipales.

Oosterbeek, L. (2012, diciembre). Desafios ambientais e culturais em contexto de crise: uma perspectiva de Gestão Integrada do Território. In Anais do Congresso Luso-Brasileiro de Interfaces multidisciplinares do Direito para a Gestão Integrada do Território, Mação, Portugal.

Programa de las Naciones Unidas para el Desarrollo. (2010). Sector rural paraguayo: una visión general para un diálogo informado. Asunción, Paraguay: Autor.

Riquelme, Q., \& Vera, E. (2013). La otra cara de la soja. El impacto del agronegocio en la agricultura campesina y en la producción de alimentos. Asunción, Paraguay: Oxfam.

Rojas Villagra, L. (2009). Actores del agro-negocio en Paraguay. Asunción, Paraguay: Diakonia - BASE-IS.

Sili, M. E. (2018). La acción territorial: una propuesta conceptual y metodológica para su análisis. Revista Brasilera de estudios Urbanos regionals, 20(1), 11-31.

Truda, G. (2008). The Dynamics of a Territory: the Main Actors of Sustainable Development in the Irno Valley. Huelva, España. Recuperado de https:// halshs.archives-ouvertes.fr/halshs-00523759/ document

Vanier, M. (2015). Demain les territoires. Capitalisme reticulaire et espace politique. Paris, Francia: Hermannn.

Vázquez, F. (2013). Ciudades intermedias y sustentabilidad urbana en Paraguay. In F. Dane (Ed.), El Desafío del desarrollo sustentable en América 
Latina. (pp. 223-243). Rio de Janeiro, RJ: Konrad Adenauer Stifung.

Vázquez, F., \& Goetz, K. (2013). Atlas de Políticas Públicas del Paraguay: tendencias y retos de intervención. Asunción, Paraguay: Ministerio de Hacienda.

Verdecchia, M. (2007, octubre). Modernización agraria en Paraguay. In Anales del Encuentro
Regional del Programa Mercosur Social y Solidario (PMSS), Asunción, Paraguay.

Victory, C. (1999, octubre). Gobiernos municipales y desarrollo local en Iberoamérica. Revista CIDOB d'afers Internationals, (47), 36.

Ward, J. H. (1963, marzo). Hierarchical Grouping to Optimize an Objective Function. Journal of the American Statistical Association, (58), 236-244.

\section{Marcelo Sili}

https://orcid.org/0000-0002-8666-0661

Doctor en Estudios Rurales por la Université Toulouse Le Mirail; Investigador Científico del CONICET (Argentina); Director del Centro ADETER y Profesor asociado del Departamento de Geografía y Turismo, Universidad Nacional del Sur. E-mail: sili.marcelo@gmail.com 


\section{ANEXOS}

\section{ANEXO 1: GUÍA DE ENCUESTA PARA EL ANÁLISIS DE LA ACCIÓN TERRITORIAL}

\section{Caracterización municipal}

1. Población del Distrito

2. ¿Cuál es la dinámica demográfica del Distrito? (crece, estable, disminuye la población)

3. ¿Cuales son las actividades agropecuarias predominantes en su Distrito?

4. Nivel de NBI del Distrito

5. ¿Cuál es el estado de las infraestructuras y servicios?

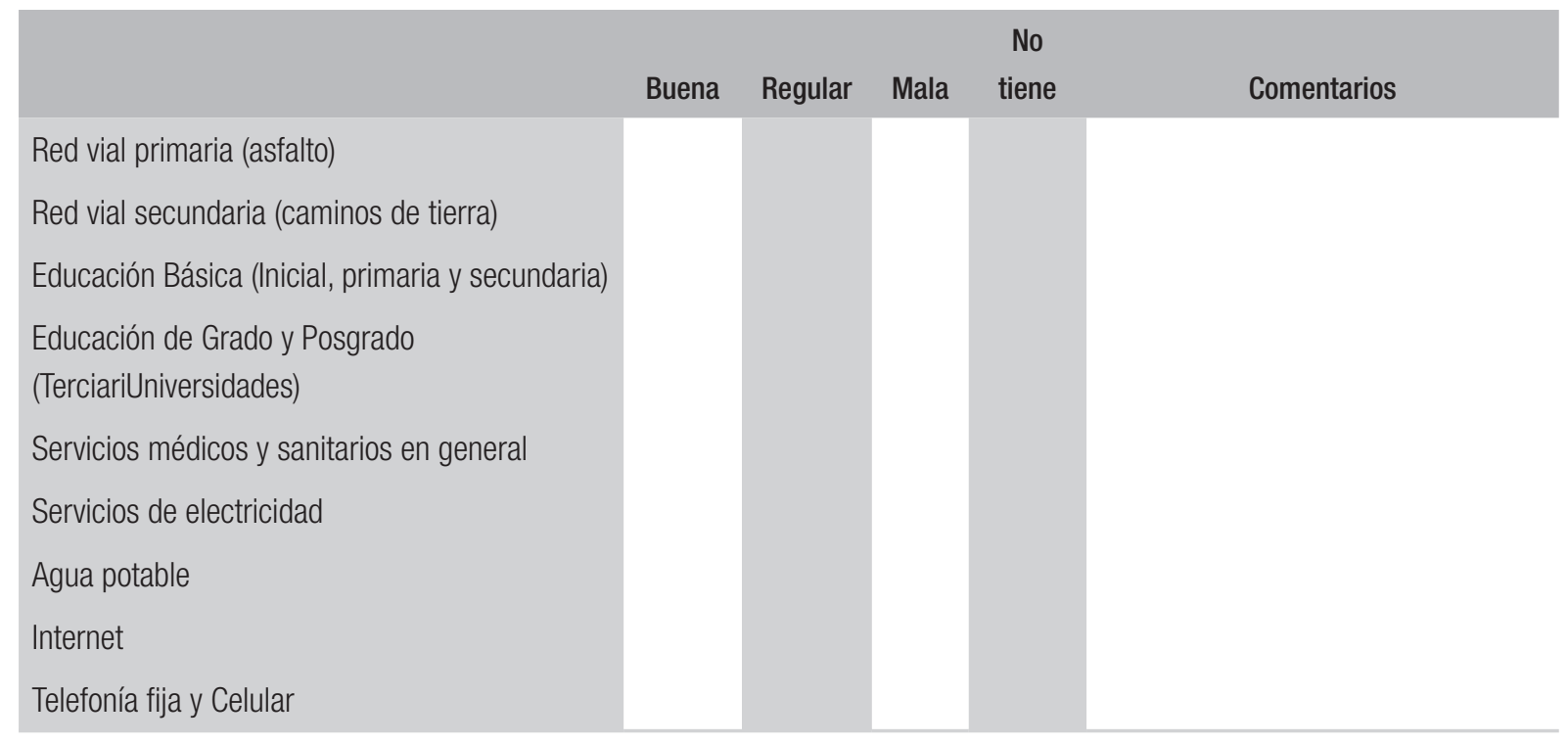

6. ¿Cuáles son los principales problemas del distrito? (mencione al menos 5 en orden jerárquico)

\section{Gestión municipal}

7. ¿Cuál es la profesión del Intendente?

8. ¿Con qué áreas administrativas cuenta la Municipalidad?

9. ¿Cuál es el nivel de capacitación de funcionarios?

10. ¿Cuál es el nivel de capacitación del personal?

11. ¿Cuál es el monto del presupuesto anual?

12.¿Cuáles son los principales problemas de la gestión municipal?

13. ¿Cuales son las principales necesidades de fortalecimiento para la gestión municipal?

\section{Acciones y gestión del desarrollo}

14. ¿Cuáles son las principales iniciativas llevadas a cabo en el Distrito para generar dinámicas de desarrollo? (mencione al menos 5 en orden jerárquico) 
15. ¿Qué actores participan en estas iniciativas para generar una mayor dinámica de desarrollo?

16. ¿Cuales son las principales acciones que se llevan a cabo en el Distrito para reducir la pobreza? (mencione al menos 5 en orden jerárquico)

17. ¿Qué actores participan en estas iniciativas para reducir la pobreza?

18. ¿Qué inhibe o limitan estas iniciativas? (falta de recursos, falta de técnicos, falta de interés y consenso por parte de la población)

19. ¿Estas acciones se plantean dentro de un plan integral de desarrollo?

20. ¿Estas acciones se vinculan con otras acciones locales o se hace sola? (Convergencia, fragmentación y descoordinación de iniciativas)

21. ¿Cuales son las principales necesidades de fortalecimiento en materia de gestión del desarrollo?

\section{ANEXO 2: TIPO DE RESPUESTAS A LAS PREGUNTAS CLAVES 6, 14 Y 16}

Pregunta 6: ¿Cuáles son los principales problemas del distrito? (ejemplo de respuestas ya categorizadas)

- Degradación del hábitat y el ambiente

- Falta y deterioro de los equipamientos y servicios públicos

- Falta de caminos

- Falta de infraestructuras básicas

- Bajo nivel de desarrollo de la agricultura familiar

- Debilidad de los Municipios

- Pobreza, desempleo y desintegración social

- Violencia e inseguridad

Pregunta 14: ¿Cuáles son las principales iniciativas llevadas a cabo en el Distrito para generar dinámicas de desarrollo? (ejemplo de respuestas ya categorizadas)

- Asistencia a la ciudadanía (entrega de subsidios para viajes a la capital, subsidios para pago gastos funerarios, entrega de material de construcción, entrega de alimentos, etc.)

- Promoción para la inversión y desarrollo productivo (entrega de semillas, laboreo de la tierra de los pequeños agricultores, coordinación con empresas privadas para gestiones, etc.)

- Planificación y gestión territorial y ambiental (plan de desarrollo local, plan de mejora ambiental de un arroyo o una zona especial, zonificación de zonas urbanas, etc.)

- Mejora de caminos y sistemas de transporte (empedrado o enripiado de caminos, pasaje de máquina vial para mantenimiento del camino rural, etc.)

- Creación y mejora de equipamientos públicos (mejora de salas médicas o escuelas, creación de un salón municipal, etc.)

- Creación de infraestructura (creación de alcantarillado, creación red de agua potable)

Pregunta 16: Cuales son las principales acciones que se llevan a cabo en el Distrito para reducir la pobreza (ejemplo de respuestas ya categorizadas)

- Capacitaciones en general a la población más pobre y vulnerable en temas de salud y producción

- Provisión de servicios básicos (agua, electricidad)

- Mejora de caminos (caminos consolidados en los asentamientos periurbanos y rurales) 
- Construcción de viviendas y acceso a terrenos (asistencia financiera para construcción de viviendas o para compra de terrenos)

- Acceso a tekopora y otros planes sociales (subsidios o ingreso universal para familias vulnerables)

- Almuerzo escolar (almuerzo en las escuelas para los alumnos de familias de bajos ingresos)

- Apoyo a la producción agrícola (apoyo con semillas, laboreo de tierras, entrega de herramientas)

- Asistencia en salud

\section{ANEXO 3: GRÁFICO DE CLUSTER}
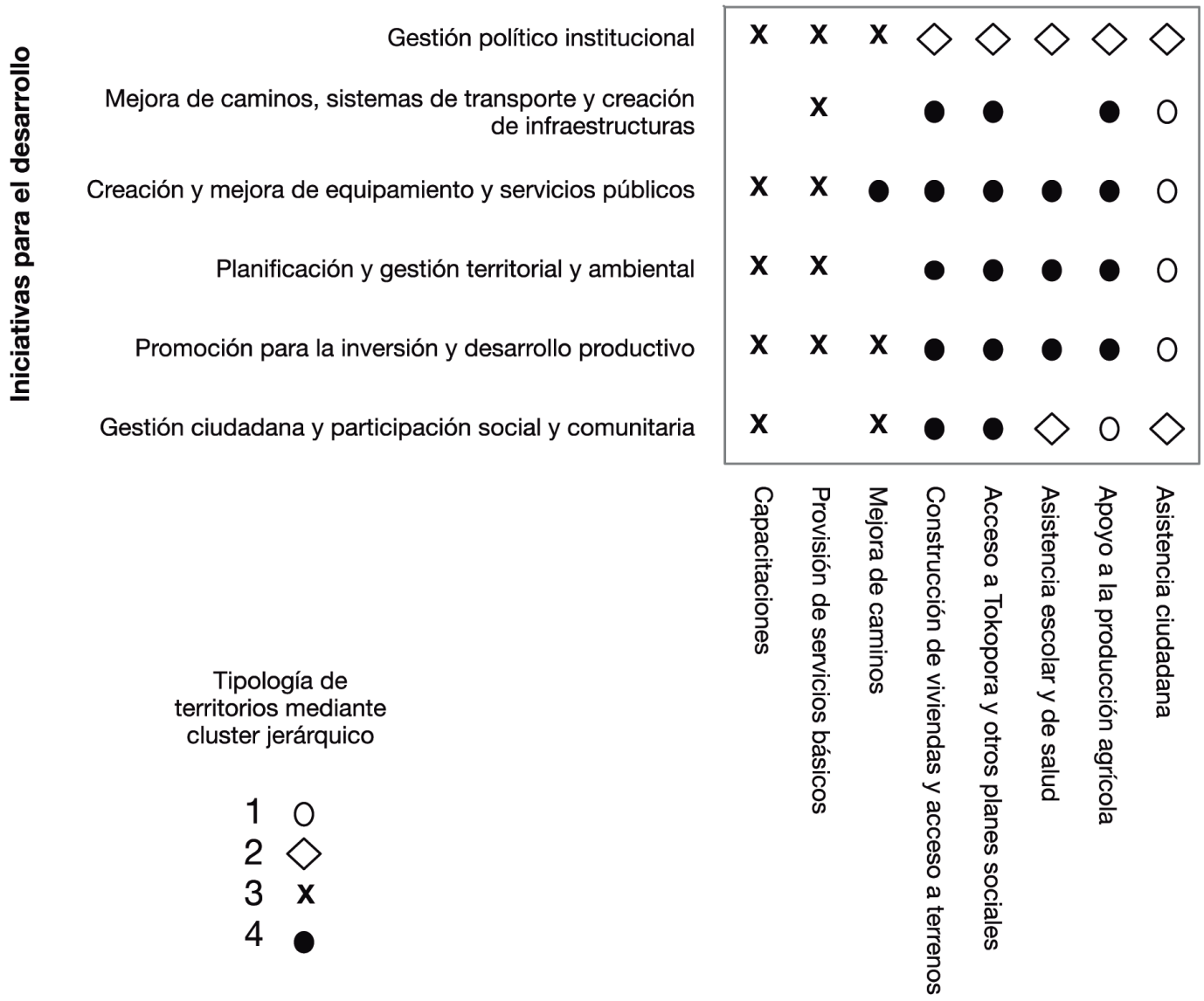

Iniciativas para la reducción de la pobreza

Fuente: Elaborado por el autor con base en el procesamiento de cluster. 